\title{
Use of diffusion-weighted MRI to modify radiosurgery planning in brain metastases may reduce local recurrence
}

\author{
Rasheed Zakaria ${ }^{1,2}$ (]) Andreas Pomschar ${ }^{3} \cdot$ Michael D. Jenkinson ${ }^{1,8}$. \\ Jörg-Christian Tonn ${ }^{4}$ Claus Belka ${ }^{5,6,7} \cdot$ Birgit Ertl-Wagner $^{3} \cdot$ Maximilian Niyazi $^{5,6,7}$
}

Received: 28 August 2016 / Accepted: 8 November 2016 / Published online: 14 November 2016

(c) The Author(s) 2016. This article is published with open access at Springerlink.com

\begin{abstract}
Stereotactic radiosurgery (SRS) is an effective and well tolerated treatment for selected brain metastases; however, local recurrence still occurs. We investigated the use of diffusion weighted MRI (DWI) as an adjunct for SRS treatment planning in brain metastases. Seventeen consecutive patients undergoing complete surgical resection of a solitary brain metastasis underwent image analysis retrospectively. SRS treatment plans were generated based on standard 3D post-contrast T1-weighted sequences at $1.5 \mathrm{~T}$ and then separately using apparent diffusion coefficient (ADC) maps in a blinded fashion. Control scans immediately post operation confirmed complete tumour resection. Treatment plans were compared to one
\end{abstract}

Rasheed Zakaria and Andreas Pomschar have contributed equally.

Rasheed Zakaria

rzakaria@nhs.net

1 Department of Neurosurgery, The Walton Centre NHS Foundation Trust, Lower Lane, Fazakerley, Liverpool L9 7LJ, UK

2 Institute of Integrative Biology, University of Liverpool, Liverpool, UK

3 Institute of Clinical Radiology, LMU Munich, Munich, Germany

4 Department of Neurosurgery, LMU Munich, Munich, Germany

5 Department of Radiation Oncology, LMU Munich, Munich, Germany

6 German Cancer Research Centre (DKFZ), Heidelberg, Germany

7 German Cancer Consortium (DKTK), Heidelberg, Germany

8 Institute of Translational Medicine, University of Liverpool, Liverpool, UK another and with volume of local recurrence at progression quantitatively and qualitatively by calculating the conformity index $(\mathrm{CI})$, the overlapping volume as a proportion of the total combined volume, where $1=$ identical plans and $0=$ no conformation whatsoever. Gross tumour volumes (GTVs) using ADC and post-contrast T1-weighted sequences were quantitatively the same (related samples Wilcoxon signed rank test $=-0.45, \mathrm{p}=0.653$ ) but showed differing conformations (CI 0.53, $\mathrm{p}<0.001$ ). The diffusion treatment volume (DTV) obtained by combining the two target volumes was significantly greater than the treatment volume based on post contrast T1-weighted MRI alone, both quantitatively (median 13.65 vs. $9.52 \mathrm{~cm}^{3}$, related samples Wilcoxon signed rank test $\mathrm{p}<0.001$ ) and qualitatively (CI $0.74, p=0.001)$. This DTV covered a greater volume of subsequent tumour recurrence than the standard plan (median $3.53 \mathrm{~cm}^{3}$ vs. $3.84 \mathrm{~cm}^{3}, \mathrm{p}=0.002$ ). ADC maps may be a useful tool in addition to the standard post-contrast T1-weighted sequence used for SRS planning.

Keywords Brain metastasis - Stereotactic radiosurgery · ADC $\cdot$ DWI $\cdot$ Planning study

\section{Introduction}

Brain metastases are increasingly common and cause significant morbidity and mortality in patients with solid tumours [1-4]. Recent analyses of the brain-brain metastasis interface [5, 6] suggest local invasion may be more important than previously thought [7] and various solutions including supra-marginal surgical resection and cavity boost stereotactic radiosurgery (SRS) have been proposed [8-10]. MRI scans of the brain are routinely obtained in the course of diagnosis and disease monitoring for these 
patients and diffusion MRI (DWI) sequences are commonly included, historically to distinguish these ring enhancing tumours from abscesses but more recently to aid in differentiating solitary metastases from glioma, for surgical planning and even to predict prognosis [11]. It is known that in human brain metastases the apparent diffusion coefficient (ADC) increases with decreasing cellularity [12] and decreasing density of intratumoral connective tissue [13]. Changes in ADC in the peritumoral brain may precede micro-metastasis appearance in animal models [14] and lower tumour ADC values have been shown to be predictive of earlier recurrence and shorter survival after neurosurgery [12,13] and SRS [15]. The aim of this study was to investigate whether the addition of an ADC map to a standard post-contrast $\mathrm{T} 1$ weighted sequence would aid SRS planning, in terms of increasing the final planned treatment volume or potentially encompassing peritumoral areas where local recurrence subsequently occurred.

\section{Materials and methods}

\section{Patients}

In this retrospective study, 17 consecutive neurosurgical patients (median age 54 years, 4 male/13 female) with a supratentorial brain metastasis who had undergone diffusion-weighted MRI (DWI) as part of their preoperative investigations and who had developed recurrence at the site of surgery (as per generic RANO criteria [16]) were included (Table 1). All patients studied underwent gross total resection and there were no complications within 30 days of operation. Median overall survival was 11.8 months (95\% CI 7.8-15.8 months) and median time to local recurrence was 8.0 months $(95 \% \mathrm{CI}$ 6.6-9.4 months).

\section{MRI and analysis}

MR imaging was performed on clinical whole body scanners at $1.5 \mathrm{~T}$ with a single channel head coil. The standard post-contrast $\mathrm{T} 1$-weighted sequence was a volumetric fast spoiled gradient echo sequence, which was acquired after the intravenous administration of Gadavist ${ }^{\circledR}$ (Bayer HealthCare, Germany) at a standard dose of $0.1 \mathrm{mmol} / \mathrm{kg}$. The acquisition parameters were as follows: repetition time (TR) $9 \mathrm{~ms}$, echo time (TE) $1.4 \mathrm{~ms}$, flip angle 15 degrees, acquisition matrix $256 \times 256$, volume $180 \times 1 \mathrm{~mm}$ axial slices at zero angulation. DWI was obtained using one acquisition over $90 \mathrm{~s}$ through single-shot echo planar imaging with $b$ values of 0 and $1000 \mathrm{~s} / \mathrm{mm}^{2}$. Using the post processing software package GE FuncTool $^{\circledR}$ (v 4.5.5, General Electric Co., Maryland, USA), an ADC map was generated for each dataset. All patients underwent a control volume CT brain on day 1 post operatively as per institutional protocol.

Table 1 Demographic and clinical information of the included patients

\begin{tabular}{|c|c|c|c|c|c|c|c|c|}
\hline ID & Age (years) & Sex & $\begin{array}{l}\text { Performance } \\
\text { status (KPS) } \\
(\%)\end{array}$ & GPA category & Primary cancer & $\begin{array}{l}\text { Extracranial } \\
\text { metastases }\end{array}$ & Status of primary tumour & $\begin{array}{l}\text { Location of } \\
\text { brain metas- } \\
\text { tasis }\end{array}$ \\
\hline M011 & 38 & $\mathrm{~F}$ & 100 & 3.0 & Melanoma (BRAF+) & Present & Stable disease & Occipital \\
\hline M013 & 48 & $\mathrm{~F}$ & 90 & $3.5-4.0$ & NSCLC & Absent & Stable disease & Frontal \\
\hline M019 & 70 & $\mathrm{~F}$ & 90 & $1.5-2.5$ & Lung NOS & Present & Synchronous & Cerebellar \\
\hline M028 & 57 & $\mathrm{~F}$ & 70 & $1.5-2.5$ & Melanoma & Present & Synchronous & Parietal \\
\hline M031 & 70 & M & 90 & 3.0 & NSCLC & Absent & Stable disease & Occipital \\
\hline M033 & 36 & $\mathrm{~F}$ & 100 & $3.5-4.0$ & NSCLC & Absent & Synchronous & Temporal \\
\hline M042 & 60 & $\mathrm{~F}$ & 70 & $1.5-2.5$ & Unknown & Present & Synchronous & Frontal \\
\hline M052 & 48 & $\mathrm{~F}$ & 90 & 3.0 & Breast (HER2-) & Present & Stable disease & Parietal \\
\hline M222 & 56 & $\mathrm{~F}$ & 90 & $3.5-4.0$ & NSCLC & Absent & Stable disease & Frontal \\
\hline M302 & 35 & $\mathrm{~F}$ & 90 & 3.0 & Melanoma (BRAF+) & Present & Stable disease & Parietal \\
\hline M008 & 54 & $\mathrm{~F}$ & 80 & 3.0 & NSCLC & Absent & Synchronous & Frontal \\
\hline M257 & 68 & M & 90 & 3.0 & NSCLC & Absent & Synchronous & Parietal \\
\hline M260 & 67 & M & 90 & 3.0 & NSCLC & Absent & Synchronous & Occipital \\
\hline M268 & 51 & M & 90 & $3.5-4.0$ & NSCLC & Absent & Stable disease & Frontal \\
\hline M308 & 56 & $\mathrm{~F}$ & 90 & $3.5-4.0$ & Breast (HER2+) & Absent & Stable disease & Frontal \\
\hline M135 & 27 & $\mathrm{~F}$ & 90 & $3.5-4.0$ & Breast (HER2-) & Absent & Stable disease & Parietal \\
\hline M164 & 53 & $\mathrm{~F}$ & 100 & $1.5-2.5$ & NSCLC & Present & Synchronous & Frontal \\
\hline
\end{tabular}




\section{Stereotactic radiosurgery planning}

Scans were transferred to Oncentra MasterPlan ${ }^{\circledR}$ (Nucletron BV, Veenendaal, Netherlands) and target delineation performed in a randomized reading order by three separate operators experienced in SRS planning and blinded to the clinical information and outcome of the patient. Different imaging sequences were contoured at different days in order to avoid pre-imaging bias. Volumetric analysis was done within MasterPlan ${ }^{\circledR}$ employing the "Case Explorer" tool. We compared treatment volumes based on the postcontrast T1-weighted scans $\left(\mathrm{GTV}_{\mathrm{Tlgad}}\right)$, using the ADC maps alone $\left(\mathrm{GTV}_{\mathrm{ADC}}\right)$ and using both sequences in combination, which we subsequently refer to as diffusion treatment volume (DTV) and then compared these with areas of subsequent recurrence after gross total resection. The conformity index is a concept in radiation oncology used to compare treatment plans and volumes and has a variety of derivations and applications. Here an intentionally simple approach is used, calculating the ratio of intersection of two volumes with their combined total volume to yield an index of their conformity from 0 , no similarity whatsoever, to 1 , identical plans (illustrated in Fig. 1).

\section{Results}

\section{Clinical outcomes}

All patients studied underwent gross total resection with no complications within 30 days of operation. Median overall survival was 11.8 months (95\% CI 7.815.8 months) and median time to local recurrence was 8.0 months (95\% CI 6.6-9.4 months). In fifteen of seventeen cases neurosurgical resection of a solitary cerebral metastasis was followed by adjuvant whole brain radiotherapy (WBRT) $30 \mathrm{~Gy}$ in 10 fractions. In one case the patient was too unwell due to systemic disease

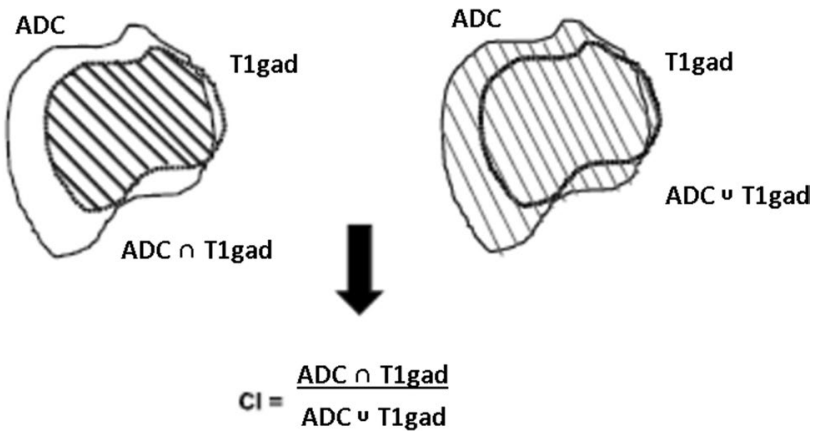

Fig. 1 Illustration of the conformity index (=intersection volume $\div$ conjunction volume) for comparing treatment volumes based on the T1gad and the ADC studies to receive WBRT and in one other 20 Gy in 5 fractions was administered at the treating oncologists' discretion. At recurrence five patients underwent re-operation, three underwent SRS and the remainder received palliative chemotherapy.

\section{Assessing treatment volumes}

Intra-class correlation coefficient showed strong agreement amongst the three different observers; for $\mathrm{GTV}_{\mathrm{T} 1 \mathrm{gad}}$ alpha $=0.998$ (95\% CI 0.992-0.999) and for $\mathrm{GTV}_{\mathrm{ADC}}$ alpha $=0.987$ (95\% CI 0.958-0.997). Direct pairwise comparison of $\mathrm{GTV}_{\mathrm{Tlgad}}$ and $\mathrm{GTV}_{\mathrm{ADC}}$ showed no quantitative difference (related samples Wilcoxon signed rank test $=-0.45, \mathrm{p}=0.653$ ); values are listed in Table 2 . The conformity index (Fig. 1) was used to qualitatively compare the volumes; mean conformity index $( \pm \mathrm{SD})$ for $\mathrm{GTV}_{\mathrm{Tlgad}}$ compared to $\mathrm{GTV}_{\mathrm{ADC}}$ was $0.53( \pm 0.16)$, which is significantly different from 1 (one sample $t$ test, $\mathrm{t}=-11.9, \mathrm{df}=16, \mathrm{p}<0.001)$. As a control, the conformity index for $\mathrm{GTV}_{\mathrm{Tlgad}}$ of different observers was calculated and found to be $0.79( \pm 0.28)$ with no significant difference from $1(\mathrm{p}>0.05)$.

Table 2 Average metastasis volume as assessed using the standard post-contrast planning sequence (T1gad) and the ADC map

\begin{tabular}{|c|c|c|c|}
\hline Case ID & $\mathrm{GTV}_{\mathrm{T1gad}}$ & $\mathrm{GTV}_{\mathrm{ADC}}$ & $\begin{array}{l}\text { DTV (union of } \\
\text { GTV }_{\text {T1gad }} \text { and } \\
\text { GTV }_{\mathrm{ADC}} \text { ) }\end{array}$ \\
\hline M011 & 18.5 & 29.81 & 30.46 \\
\hline M013 & 10.2 & 12.57 & 13.65 \\
\hline M019 & 38.99 & 27.88 & 44.82 \\
\hline M028 & 12.33 & 9.4 & 14.23 \\
\hline M031 & 49.48 & 42.35 & 55.36 \\
\hline M033 & 16.03 & 10.07 & 16.89 \\
\hline M042 & 71.71 & 64.51 & 77.21 \\
\hline M052 & 4.33 & 4.27 & 5.77 \\
\hline M222 & 7.27 & 6.8 & 9.31 \\
\hline M302 & 14.18 & 18.58 & 19.87 \\
\hline M008 & 2.35 & 1.5 & 2.37 \\
\hline M257 & 4.41 & 5.48 & 6.70 \\
\hline M260 & 0.75 & 0.49 & 0.84 \\
\hline M268 & 4.85 & 7.56 & 8.18 \\
\hline M308 & 9.52 & 7.05 & 12.45 \\
\hline M135 & 8.74 & 15.06 & 16.35 \\
\hline M164 & 1.19 & 1.74 & 2.24 \\
\hline Median & 9.52 & 9.40 & 13.65 \\
\hline
\end{tabular}

Volumes are in $\mathrm{cm}^{3}$ 


\section{Combining the ADC map with standard planning}

The DTV was significantly greater than the $\mathrm{GTV}_{\text {Tlgad }}$ both quantitatively (related samples Wilcoxon signed rank test $=3.621, \mathrm{p}<0.001$ ) and qualitatively (conformity index $=0.74( \pm 0.17)$, significantly different to 1 , $\mathrm{t}=-6.27, \mathrm{p}=0.001)$. There was no significant difference in the volume of recurrent tumour that would have been covered by the $\mathrm{GTV}_{\mathrm{T} 1 \mathrm{gad}}$ vs. the $\mathrm{GTV}_{\mathrm{ADC}}(3.53$ and $3.57 \mathrm{~cm}^{3}$ respectively, Wilcoxon related samples test $=-0.052, p=0.959)$ and the conformity index was not significantly different $\left(0.20 \pm 0.16\right.$ for $\mathrm{GTV}_{\mathrm{ADC}}$ vs. $0.22 \pm 0.20$ for $\mathrm{GTV}_{\mathrm{T} 1 \mathrm{gad}}$, paired $t$ test $=0.823, \mathrm{p}=0.424$ ). The volume of recurrence encompassed by the DTV was significantly greater than the $\mathrm{GTV}_{\mathrm{T} 1 \mathrm{gad}}$ in 12 of 16 individual cases as well as overall for the group (median $3.84 \mathrm{cc}$, range $0-32$, vs. $3.53 \mathrm{cc}$, range $0-31$ ), Wilcoxon related samples test $=-3.061, \mathrm{p}=0.002$; this is illustrated for one case (M-011) in Fig. 2.

\section{Discussion}

We have shown that using an ADC map in addition to a conventional post-contrast T1-weighted MRI sequence to plan radiosurgery for solitary brain metastases results in a greater treatment volume with a different conformation compared to the standard protocol. Furthermore, this combined treatment volume intersects with a greater volume of subsequent local recurrence of that metastasis following complete resection. This analysis suggests the ADC map to provide additional, different, clinically useful information compared to the post-contrast T1-weighted sequence alone.

Local recurrence occurs in approximately $20 \%$ of cases following radiosurgery [17] and poses a clinical problem for patients and clinicians. ADC is known to decrease with increasing cellularity. Unlike arbitrarily increasing the treated volume, which has not consistently been shown to reduce local recurrence [18] and may risk radionecrosis to normal brain [19], using the ADC map to plan SRS may therefore cover biologically active areas, although it
Fig. 2 An occipital metastasis in a patient with metastatic melanoma (M-011). Treatment plans were generated based on a the $\mathrm{ADC}$ map- $-\mathrm{GTV}_{\mathrm{ADC}}$ and b the post-contrast T1-weighted planning study $-\mathrm{GTV}_{\mathrm{Tlgad}}$. The combined plan with addition of these two volumes is termed the diffusion treatment volume or DTV (c). These volumes are superimposed on postcontrast T1-weighted sequences acquired at the point when the resected tumour recurred. The volume of local recurrence that was covered by the $\mathrm{GTV}_{\mathrm{Tigad}}$ (d) was less than that covered by the DTV (e) and differed in conformation
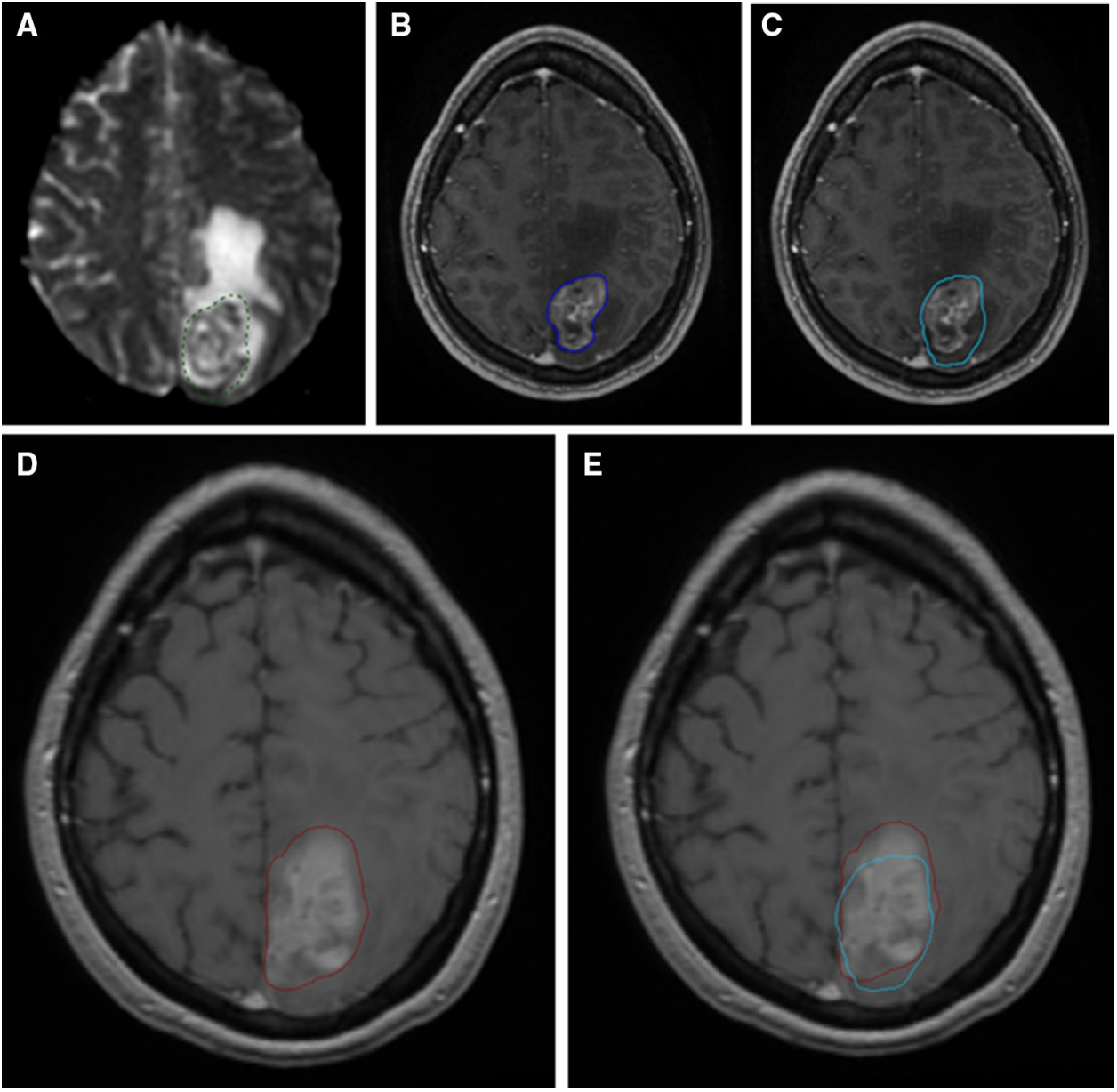
is likely that $\mathrm{ADC}$ changes represent a generalized overall assessment of the underlying biological and pathological processes. ADC changes have been used in a radiotherapy planning study to distinguish high-risk areas for glioblastoma recurrence [20]; however, to our knowledge DWI has never been applied to metastasis radiosurgery planning before. The only investigations into SRS planning for brain metastases that focussed on combining metabolic with anatomic imaging by using FDG-PET [21, 22]; this study resulted in modified treatment plans for $2 / 3$ of brain metastases in a series of 8 lesions. One further study fitted 11-C methionine PET to the contrast-enhancing border [23] using a simple model to provide metabolic tumour delineation, but did not look at outcome parameters.

There are limitations to our study that need to be taken into account when interpreting the data. Our study design is retrospective in nature, which, however, offered the advantage of a complete follow-up from time of diagnosis to death. Further prospective studies could evaluate SRS planning based on the ADC map and the post-contrast T1-weighted MRI followed by comparison of subsequent local recurrence with the original plans. Nevertheless, our pilot study confirms that diffusion-based plans were of reasonable quality and detail. Moreover, the extent of coverage of such plans in regard to surrounding brain tissue and the technical integration of diffusion-weighted imaging into a planning software could be demonstrated. At this point in time, ADC may not routinely be added for GTV definition in SRS as normal tissue constraints have to be considered and tumour volumes tend to be larger when applying the DTV concept as presented. However, if our preliminary data are confirmed in future studies, this limitation may be overcome by hypo-fractionated stereotactic treatments as the risk-benefit ratio will be improved with increasing tumour size.

Funding Rasheed Zakaria is supported by the Medical Research Council, UK (MR/L017342/1) and the Royal College of Surgeons, England.

\section{Compliance with ethical standards}

Conflict of interest The authors have no financial conflicts of interest to declare.

Ethical approval Ethical approval was granted as an internal project within the institution's Research Tissue Bank (National Research Ethics Service \# 11/WNo03/2) for which patients gave written consent for inclusion.

Open Access This article is distributed under the terms of the Creative Commons Attribution 4.0 International License (http:// creativecommons.org/licenses/by/4.0/), which permits unrestricted use, distribution, and reproduction in any medium, provided you give appropriate credit to the original author(s) and the source, provide a link to the Creative Commons license, and indicate if changes were made.

\section{References}

1. Ostrom QT, Gittleman H, Liao P, Rouse C, Chen Y, Dowling J, Wolinsky Y, Kruchko C, Barnholtz-Sloan J (2014) CBTRUS statistical report: primary brain and central nervous system tumors diagnosed in the United States in 2007-2011. Neuro-oncology 16(Suppl 4):iv1-iv63. doi:10.1093/neuonc/nou223

2. Nayak L, Lee EQ, Wen PY (2012) Epidemiology of brain metastases. Curr Oncol Rep 14:48-54. doi:10.1007/ s11912-011-0203-y

3. Davis FG, Dolecek TA, McCarthy BJ, Villano JL (2012) Toward determining the lifetime occurrence of metastatic brain tumors estimated from 2007 United States cancer incidence data. Neurooncology 14:1171-1177. doi:10.1093/neuonc/nos152

4. Jenkinson MD, Haylock B, Shenoy A, Husband D, Javadpour M (2011) Management of cerebral metastasis: evidence-based approach for surgery, stereotactic radiosurgery and radiotherapy. Eur J Cancer 47:649-655. doi:10.1016/j.ejca.2010.11.033

5. Berghoff AS, Rajky O, Winkler F, Bartsch R, Furtner J, Hainfellner JA, Goodman SL, Weller M, Schittenhelm J, Preusser M (2013) Invasion patterns in brain metastases of solid cancers. Neuro-oncology 15:1664-1672. doi:10.1093/neuonc/not112

6. Siam L, Bleckmann A, Chaung HN, Mohr A, Klemm F, Barrantes-Freer A, Blazquez R, Wolff HA, Luke F, Rohde V, Stadelmann C, Pukrop T (2015) The metastatic infiltration at the metastasis/brain parenchyma-interface is very heterogeneous and has a significant impact on survival in a prospective study. Oncotarget 6:29254-29267. doi:10.18632/oncotarget.4201

7. Baumert BG, Rutten I, Dehing-Oberije C, Twijnstra A, Dirx MJ, Debougnoux-Huppertz RM, Lambin P, Kubat B (2006) A pathology-based substrate for target definition in radiosurgery of brain metastases. Int J Radiat Oncol Biol Phys 66:187-194. doi:10.1016/j.ijrobp.2006.03.050

8. Roberge D, Parney I, Brown PD (2012) Radiosurgery to the postoperative surgical cavity: who needs evidence? Int J Radiat Oncol Biol Phys 83:486-493. doi:10.1016/j.ijrobp.2011.09.032

9. Yoo H, Kim YZ, Nam BH, Shin SH, Yang HS, Lee JS, Zo JI, Lee SH (2009) Reduced local recurrence of a single brain metastasis through microscopic total resection. J Neurosurg 110:730 736. doi:10.3171/2008.8.JNS08448

10. Patel AJ, Suki D, Hatiboglu MA, Abouassi H, Shi W, Wildrick DM, Lang FF, Sawaya R (2010) Factors influencing the risk of local recurrence after resection of a single brain metastasis. $\mathrm{J}$ Neurosurg 113:181-189. doi:10.3171/2009.11.JNS09659

11. Zakaria R, Das K, Bhojak M, Radon M, Walker C, Jenkinson MD (2014) The role of magnetic resonance imaging in the management of brain metastases: diagnosis to prognosis. Cancer Imaging 14:8. doi:10.1186/1470-7330-14-8

12. Zakaria R, Das K, Radon M, Bhojak M, Rudland PR, Sluming V, Jenkinson MD (2014) Diffusion-weighted MRI characteristics of the cerebral metastasis to brain boundary predicts patient outcomes. BMC Med Imaging 14:26. doi:10.1186/1471-2342-14-26

13. Berghoff AS, Spanberger T, Ilhan-Mutlu A, Magerle M, Hutterer M, Woehrer A, Hackl M, Widhalm G, Dieckmann K, Marosi C, Birner P, Prayer D, Preusser M (2013) Preoperative diffusionweighted imaging of single brain metastases correlates with patient survival times. PloS One 8:e55464. doi:10.1371/journal. pone. 0055464

14. Serres S, Martin CJ, Sarmiento Soto M, Bristow C, O’Brien ER, Connell JJ, Khrapitchev AA, Sibson NR (2014) Structural and functional effects of metastases in rat brain determined by multimodal MRI. Int J Cancer 134:885-896. doi:10.1002/ijc.28406

15. Lee CC, Wintermark M, Xu Z, Yen CP, Schlesinger D, Sheehan JP (2014) Application of diffusion-weighted magnetic resonance imaging to predict the intracranial metastatic tumor response 
to gamma knife radiosurgery. J Neurooncol 118:351-361. doi:10.1007/s11060-014-1439-9

16. Quant EC, Wen PY (2011) Response assessment in neuro-oncology. Curr Oncol Rep 13:50-56. doi:10.1007/s11912-010-0143-y

17. Kocher M, Soffietti R, Abacioglu U, Villa S, Fauchon F, Baumert BG, Fariselli L, Tzuk-Shina T, Kortmann RD, Carrie C, Ben Hassel M, Kouri M, Valeinis E, van den Berge D, Collette S, Collette L, Mueller RP (2011) Adjuvant whole-brain radiotherapy versus observation after radiosurgery or surgical resection of one to three cerebral metastases: results of the EORTC 22952-26001 study. J Clin Oncol 29: 134-141. doi:10.1200/ jco.2010.30.1655

18. Kirkpatrick JP, Wang Z, Sampson JH, McSherry F, Herndon JE 2nd, Allen KJ, Duffy E, Hoang JK, Chang Z, Yoo DS, Kelsey CR, Yin FF (2015) Defining the optimal planning target volume in image-guided stereotactic radiosurgery of brain metastases: results of a randomized trial. Int J Radiat Oncol Biol Phys 91:100-108. doi:10.1016/j.ijrobp.2014.09.004

19. Kocher M, Wittig A, Piroth MD, Treuer H, Seegenschmiedt H, Ruge M, Grosu AL, Guckenberger M (2014) Stereotactic radiosurgery for treatment of brain metastases. A report of the DEGRO Working Group on Stereotactic Radiotherapy. Strahlenther Onkol 190:521-532. doi:10.1007/s00066-014-0648-7

20. Park JY, Suh TS, Lee JW, Ahn KJ, Park HJ, Choe BY, Hong S (2015) Dosimetric effects of magnetic resonance imaging-assisted radiotherapy planning: dose optimization for target volumes at high risk and analytic radiobiological dose evaluation. J Korean Med Sci 30:1522-1530. doi:10.3346/ jkms.2015.30.10.1522

21. Levivier M, Massager N, Wikler D, Lorenzoni J, Ruiz S, Devriendt D, David P, Desmedt F, Simon S, Van Houtte P, Brotchi J, Goldman S (2004) Use of stereotactic PET images in dosimetry planning of radiosurgery for brain tumors: clinical experience and proposed classification. J Nucl Med 45:1146-1154

22. Levivier M, Wikier D, Goldman S, David P, Metens T, Massager N, Gerosa M, Devriendt D, Desmedt F, Simon S, Van Houtte P, Brotchi J (2000) Integration of the metabolic data of positron emission tomography in the dosimetry planning of radiosurgery with the gamma knife: early experience with brain tumors. Technical note. J Neurosurg 93(Suppl 3):233-238. doi:10.3171/ jns.2000.93.supplement

23. Tang BN, Van Simaeys G, Devriendt D, Sadeghi N, Dewitte O, Massager N, David P, Levivier M, Goldman S (2008) Threedimensional Gaussian model to define brain metastasis limits on 11C-methionine PET. Radiother Oncol 89:270-277. doi:10.1016/j.radonc.2008.07.029 